\title{
RADIOCARBON MEASUREMENTS OF TREE RINGS FROM 14 ka HUON PINE
}

\author{
$\mathrm{T}_{\text {Lange }}^{1,2} \cdot \mathrm{M}^{\text {Barbetti }}{ }^{3} \cdot \mathrm{D} \mathrm{J}$ Donahue ${ }^{1}$ \\ ABSTRACT. We have measured the radiocarbon content of tree rings from a section of Huon pine retrieved from Tasmania. \\ The sample was divided into 39 five-ring sub-samples covering a period of 194 years. Radiocarbon ages of each of these sub- \\ samples was determined by making four measurements of each sub-sample at the Arizona AMS laboratory (Table 1). The \\ resulting $1 \sigma$ precisions are about $0.5 \%$. A comparison of our data with the appropriate curve in INTCAL98 indicates that the \\ calendar age of our sample is close to 14,000 cal BP. Using this age calibration, we have constructed a plot of $\Delta^{14} \mathrm{C}$ versus \\ assumed calendar age. This plot shows an essentially constant value over the youngest 125 rings of our sample. Over the old- \\ est $75 \mathrm{yr}$ of the sample, the $\Delta^{14} \mathrm{C}$ curve exhibits three fluctuations, the largest of which is about $65 \%$ o. The time of the peaks \\ in the Huon-pine ${ }^{14} \mathrm{C}$ curve corresponds approximately with the European Bølling/Allerød climatic event. Work is in progress \\ to extend the data $100 \mathrm{yr}$ more toward older ages.
}

\section{INTRODUCTION}

Radiocarbon dating can yield important information to a wide variety of fields. Without calendar age calibration, only an approximate date for an event can be determined. Calibration curves, relating ${ }^{14} \mathrm{C}$ ages to calendar ages, are of great importance. There are several different materials that have been found and used which can yield the information needed to create calibration curves. These include corals, varves, and tree rings, to name a few (Stuiver et al. 1998). The focus of this study is tree rings from Lagarostrobos franklinii, more commonly known as Huon pine. Huon pine is a conifer found only in the rainforest regions of southern and western Tasmania. Although extremely slow growing, the tree can attain heights of over $40 \mathrm{~m}$. Huon pine increases in diameter at an average rate of a mere $1 \mathrm{~mm}$ per year, with ring widths varying from $0.3 \mathrm{~mm}$ to $2 \mathrm{~mm}$, depending on meteorological conditions. Huon pine can reach prodigious ages, in excess of $2000 \mathrm{yr}$, making it one of the longest living organisms on earth, exceeded only by the bristle-cone pine of North America. It is also very resistant to decay due to the presence of a natural oil methyl eugenol. All of these properties make Huon pine an ideal subject for calendar age calibration studies.

\section{METHODS}

The logs chosen for this study, labeled SRT 698-1 and SRT 702-1, were excavated by a team of scientists in Tasmania. The excavation site was the Stanley River Valley $\left(41^{\circ} 42^{\prime} \mathrm{S}, 145^{\circ} 17^{\prime} \mathrm{E}\right)$, at a depth of about $3.5 \mathrm{~m}$. The logs were then cleaned, cut into sections, transported to the lab, and sanded for ringwidth measurements. A portion of each section was then sent to the NSF-Arizona AMS Facility. Upon arrival, SRT 698-1 was re-sanded, to better reveal the ring pattern, and cut into 5 ring samples under a microscope. This yielded 39 samples, covering approximately 194 years of growth. Thin slices of the samples received the following pretreatment to remove any non-native carbon:

1. Soak in $3 \mathrm{~N}$ HCL overnight to remove inorganic carbons.

2. Rinse to neutral $\mathrm{pH}$ with type-1 water.

3. Soak in $2 \% \mathrm{NaOH}$ overnight to remove mobile carbons (i.e.: humic or fulvic acids).

4. Rinse to neutral $\mathrm{pH}$ with type-1 water.

5. Soak in $3 \mathrm{~N} \mathrm{HCL}$ to neutralize any remaining $\mathrm{NaOH}$.

6. Rinse to neutral $\mathrm{pH}$ with type-1 water.

${ }^{1}$ NSF-Arizona AMS Facility, University of Arizona, Tucson, Arizona, 85721, USA

${ }^{2}$ Corresponding author. Email: lange@ newton.physics.arizona.edu.

${ }^{3}$ NWG Macintosh Centre for Quaternary Dating, University of Sydney, NSW 2006, Australia

(C) 2001 by the Arizona Board of Regents on behalf of the University of Arizona

RADIOCARBON, Vol 43, Nr 2A, 2001, p 449-452

Proceedings of the 17 th International ${ }^{14} \mathrm{C}$ Conference, edited by I Carmi and E Boaretto 


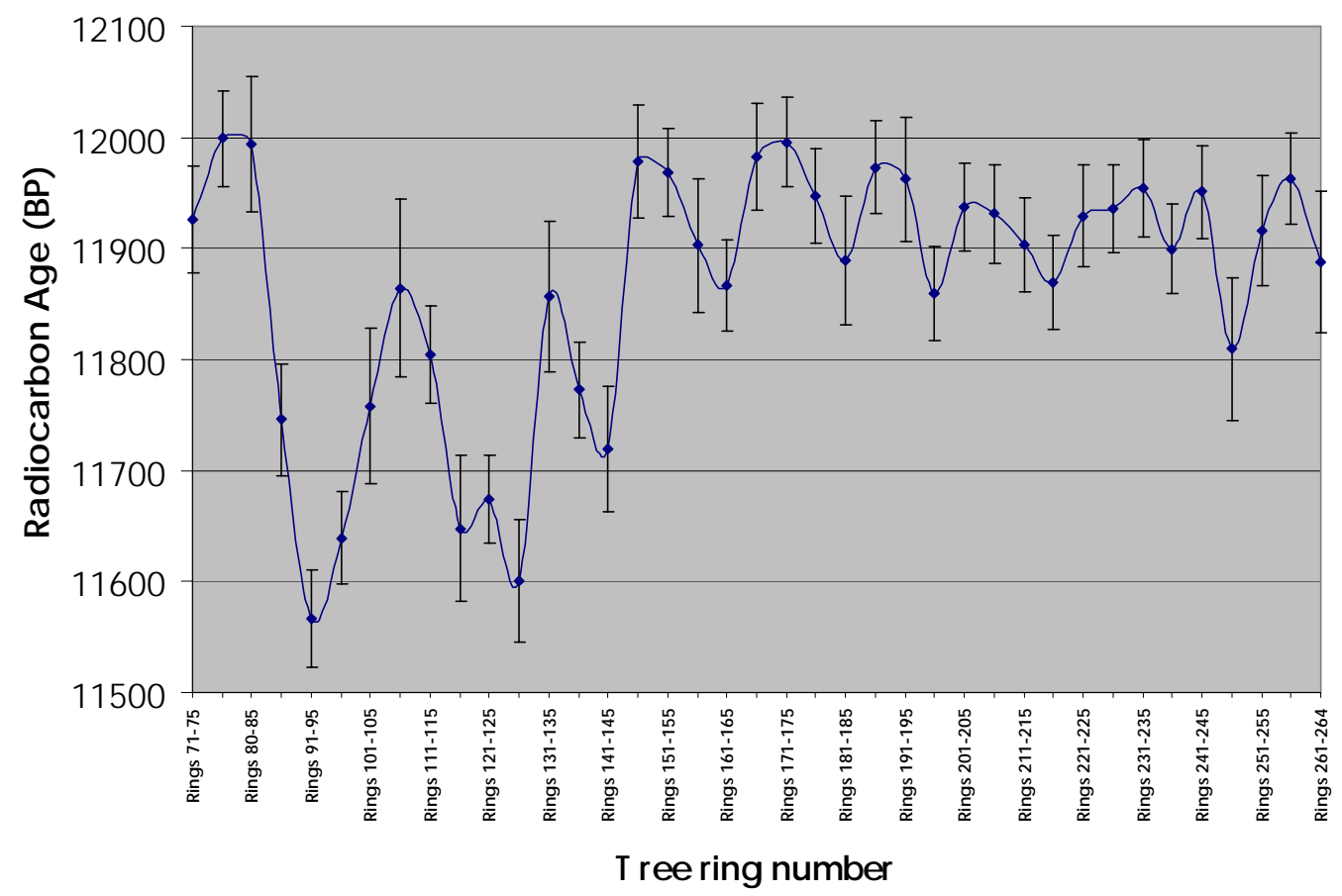

Figure 1 Radiocarbon age versus tree-ring number shows a significant event occurring in the first 75 years of the sample

$\mathrm{CO}_{2}$ was extracted using standard AMS combustion procedures. The gas was passed through several clean-up traps, measured and reduced to graphite. Each sample was measured four separate times on a General Ionex 2.3 MV Cockroft-Walton Accelerator, yielding a precision of approximately $0.5 \%$.

\section{RESULTS AND DISCUSSION}

A plot of ${ }^{14} \mathrm{C}$ age versus tree-ring number is given in Figure 1 (above), where

Radiocarbon age $=-\tau_{\text {Libby }} \ln (F)$

with $\tau_{\text {Libby }}=8033 \mathrm{yr}$

and

$$
F=\frac{\left(\frac{14}{13}\right)_{\text {Sample }[-25]}}{\left(\frac{14}{13}\right)_{1950[-25]}}
$$

(Donahue et al. 1990). Figure 1 shows a substantial peak within the first 75 (oldest) rings. Comparison of the results with the INTCAL98 calibration curve indicates that the oldest of the tree rings illustrated in Figure 1 is about 14,000 cal BP. We assumed a calendar age of 14,000 cal BP for the oldest ring set and then assigned assumed calendar ages to each subsequent 5-yr set of tree rings (see Table 1). 
We use these assumed calendar ages to calculate the values of $\Delta^{14} \mathrm{C}$, where

$$
\Delta^{14} \mathrm{C}=1000\left(\mathrm{Fe}^{\frac{\mathrm{t}}{\tau}}-1\right)
$$

with $\tau=8267 \mathrm{yr}$, and $t=$ assumed calendar age (BP).

Table 1 Radiocarbon content and assumed calendar age of Huon pine samples

\begin{tabular}{|c|c|c|c|c|c|}
\hline Lab ID & Ring Number & ${ }^{14} \mathrm{C}$ AGE & $\sigma_{(\mathbf{1 4 C})}$ & $\begin{array}{c}\text { Assumed } \\
\text { Calendar Age } \\
\text { (BP) }\end{array}$ & $\Delta^{14} \mathbf{C}$ \\
\hline AA32795 & Rings 71-75 & 11926 & 47 & 14100 & 247.4 \\
\hline AA32796 & Rings 76-80 & 11999 & 43 & 14095 & 235.3 \\
\hline AA32797 & Rings $81-85$ & 11994 & 61 & 14090 & 235.4 \\
\hline AA32798 & Rings 86-90 & 11746 & 50 & 14085 & 273.3 \\
\hline AA32799 & Rings 91-95 & 11566 & 44 & 14080 & 301.3 \\
\hline AA32800 & Rings 96-100 & 11639 & 42 & 14075 & 288.8 \\
\hline AA32801 & Rings 101-105 & 11758 & 70 & 14070 & 269.1 \\
\hline AA32802 & Rings 106-110 & 11864 & 80 & 14065 & 251.7 \\
\hline AA32803 & Rings 111-115 & 11804 & 44 & 14060 & 260.4 \\
\hline AA32804 & Rings 116-120 & 11648 & 66 & 14055 & 284.3 \\
\hline AA32805 & Rings 121-125 & 11674 & 40 & 14050 & 279.3 \\
\hline AA32806 & Rings 126-130 & 11601 & 55 & 14045 & 290.3 \\
\hline AA32807 & Rings 131-135 & 11857 & 68 & 14040 & 249.1 \\
\hline AA32808 & Rings $136-140$ & 11773 & 43 & 14035 & 261.4 \\
\hline AA32809 & Rings 141-145 & 11719 & 57 & 14030 & 269.1 \\
\hline AA32810 & Rings $146-150$ & 11978 & 51 & 14025 & 228.1 \\
\hline AA32811 & Rings 151-155 & 11969 & 40 & 14020 & 228.8 \\
\hline AA32812 & Rings $156-160$ & 11903 & 60 & 14015 & 238.2 \\
\hline AA32813 & Rings 161-165 & 11867 & 41 & 14010 & 243.0 \\
\hline AA32814 & Rings $166-170$ & 11982 & 48 & 14005 & 224.5 \\
\hline AA32815 & Rings $171-175$ & 11996 & 40 & 14000 & 221.7 \\
\hline AA32816 & Rings $176-180$ & 11947 & 43 & 13995 & 228.3 \\
\hline AA32817 & Rings 181-185 & 11889 & 58 & 13990 & 236.5 \\
\hline AA32818 & Rings $186-190$ & 11973 & 42 & 13985 & 222.9 \\
\hline AA32819 & Rings 191-195 & 11962 & 56 & 13980 & 223.9 \\
\hline AA32820 & Rings $196-200$ & 11859 & 42 & 13975 & 238.9 \\
\hline AA32821 & Rings 201-205 & 11937 & 40 & 13970 & 226.3 \\
\hline AA32822 & Rings $206-210$ & 11931 & 45 & 13965 & 226.4 \\
\hline AA32823 & Rings $211-215$ & 11903 & 43 & 13960 & 229.9 \\
\hline AA32824 & Rings $216-220$ & 11870 & 43 & 13955 & 234.3 \\
\hline AA32825 & Rings $221-225$ & 11929 & 46 & 13950 & 224.5 \\
\hline AA32826 & Rings $226-230$ & 11936 & 39 & 13945 & 222.7 \\
\hline AA32827 & Rings 231-235 & 11954 & 43 & 13940 & 219.2 \\
\hline AA32828 & Rings $236-240$ & 11899 & 40 & 13935 & 226.8 \\
\hline AA32829 & Rings $241-245$ & 11951 & 42 & 13930 & 218.2 \\
\hline
\end{tabular}


A plot of $\Delta^{14} \mathrm{C}$ versus assumed calendar age is shown in Figure 2. Although the magnitude of the peaks would change, the structure of the data in this curve would not be affected by a change in the assumed calendar age of several hundred years. The curve shows three peaks at approximately the time of the Bølling/Allerød climate event. The oldest of these peaks increases by $65 \%$, to its maximum, in 10 years. This $6 \%$ per year increase is about a factor of four greater than the rate that can be produced even by a complete shutdown of ocean circulation (Stuiver et al. 1998). In addition, the geomagnetic field during this period is well known and was essentially constant (Laj et al. 2000). Therefore, the observed high rate of change of $\Delta^{14} \mathrm{C}$ suggests that a significant increase in the production rate of ${ }^{14} \mathrm{C}$ must have occurred during this period.

To better define the shape of the curves shown in Figures 1 and 2, and to more accurately fix the time scale, we are currently extending our data back an additional $75 \mathrm{yr}$, and sampling at an interval of $2.5 \mathrm{yr}$.

\section{$\Delta^{14} \mathrm{C}$ vs Assumed Calendar Age(BP)}

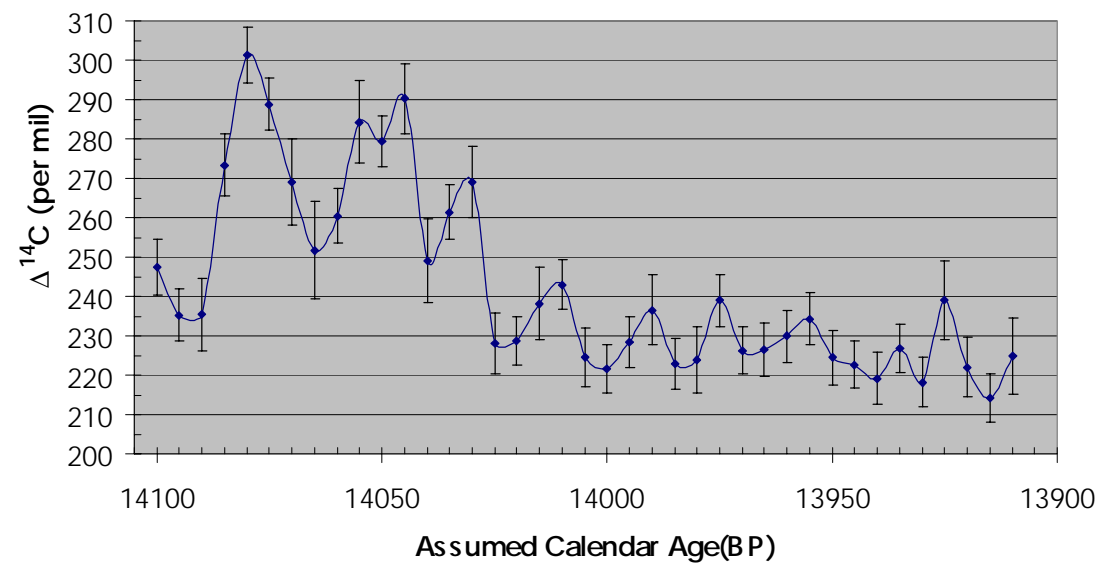

Figure 2 Comparison with INTCAL98 gives an initial "best guess" calendar age, for the event allowing us to calculate $\Delta^{14} \mathrm{C}$ values for this sequence of tree rings. We see a $65 \%$ increase of ${ }^{14} \mathrm{C}$ in 10 years at approximately $14,000 \mathrm{BP}$.

\section{ACKNOWLEDGMENTS}

We acknowledge Dr W Beck, Dr G Burr, Dr A J T Jull, Mr D Biddulph, and Ms L Hewitt at the NSF Arizona AMS Facility, Arizona, USA, Dr E Cook at Lamont-Doherty Earth Observatory, New York, USA, and Mr B Thomson and Ms Y Zhao at the NWG Macintosh Centre for Quaternary Dating, Sydney, Australia for their assistance in this work.

\section{REFERENCES}

Donahue DJ, Linick TW, Jull AJT. 1990. Isotope-ratio and background corrections for accelerator mass spectrometry radiocarbon measurements. Radiocarbon 32(2): 135-42.

Laj C, Kissel C, Mazaud A, Channell JET, Beer J. 2000. North Atlantic paleointesity stack since 75 ka (NAPIS_75) and the duration of the Laschamp event.
Philosophical Transactions of the Royal Society of London A358:1009-25.

Stuiver M, Reimer PJ, Bard E, Beck W, Burr GS, Hughen KA, Kromer B, McCormac G, van der Plicht J, Spurk M. 1998. INTCAL98 radiocarbon age calibration. Radiocarbon 40(3):1056-83. 